\title{
CADEIA DE SUPRIMENTOS: UMA ANÁLISE A PARTIR DA TEORIA DOS CUSTOS DE TRANSAÇÃO, DA TEORIA DOS CUSTOS DE MENSURAÇÃO E DA VISÃO BASEADA EM RECURSOS
}

\section{SUPPLY CHAIN: ANALYSIS UNDER PERSPECTIVE OF TRANSACTION COSTS THEORY, MEASUREMENT COSTS THEORY AND RESOURCE-BASED VIEW}

\author{
Cleiciele Albuquerque Augusto \\ Universidade Federal de Santa Catarina \\ UFSC \\ cleicielealbuquerque@yahoo.com.br
}

José Paulo de Souza

Universidade Estadual de Maringá

UEM

jpsouza@uem.br

Rolf Hermann Erdmann

Universidade Federal de Santa Catarina

UFSC

erdmann@cse.ursc.br

Antônio Ferraz Cario

Universidade Federal de Santa Catarina

UFSC

fecario@yahoo.com.br

Submissão: $31 / 07 / 2013$

Aprovação: 18/05/2015 


\title{
RESUMO
}

O objetivo nesta investigação foi o de compreender como a gestão da cadeia de suprimentos pode ser explicada a partir dos pressupostos presentes nas teorias da TCT, TCM e VBR. Para tanto, realizou-se uma pesquisa bibliográfica, do tipo descritiva e exploratória, com recorte transversal. Os resultados demonstraram que, em relação à TCT, a cadeia de suprimentos pode ser vista como um conjunto de contratos, cuja coordenação favorece a redução dos custos de transação. No que tange à TCM, a cadeia de suprimentos pode ser considerada como um conjunto de trocas de direito de propriedade, envolvendo a decomposição das transações em dimensões mensuráveis, um sistema de controle e informações que permitem que esses direitos sejam garantidos. Sob a ótica da VBR, a cadeia de suprimentos pode ser vista como um conjunto de recursos e capacidades presentes nas trocas entre os integrantes da cadeia, sendo influenciadas pela heterogeneidade das empresas e pelo seu path dependence. Conclui-se, portanto, que a cadeia de suprimentos envolve mais que o planejamento e execução do fluxo de matérias, informações e recursos financeiros, abrangendo fluxos entre estruturas de governança, características transacionais (frequência, incertezas, ativos específicos e aspectos comportamentais), direitos de propriedade, recursos, capacidades e interesses estratégicos.

Palavras-chave: Gestão da cadeia de suprimentos. Custos de transação. Custos de mensuração. Visão Baseada em Recursos.

\begin{abstract}
The comprehension of how supply chain management could be explained considering the assumptions in Transaction Cost Theory, Measurement Cost Theory and Resource-Based View is the objective in this article. In this way, a descriptive, exploratory and bibliographic research was conducted, in a crosscut perspective. The results demonstrated that, in TCT view, supply chain could be seen as a hole of contracts, whose coordinate system can reduce transaction costs. With respect to TCM, supply chain can be considered as a set of property rights exchange, involving decoupled attributes in measure dimensions and an informational control that guaranty property rights. In VBR, supply chain is viewed under the consideration of resources and capabilities. These characteristics are presents in chain agents, influenced by firm heterogeneity and path dependence. We conclude, therefore, that the supply chain involves more than the planning and execution of the flow of materials, information and financial resources. Its management includes flows between governance structures, transactional characteristics (frequency, uncertainty, specific assets and behavioral aspects), property rights, resources, capabilities and strategic interests.
\end{abstract}

Keywords: Supply chain management. Transaction costs. Measuring costs. Resource Based View. 
De acordo com Pinto (2006, p. 147), "uma cadeia de fornecimento (supply chain) é uma sequência de empresas que, estando interligadas entre si, fornecem produtos e/ou serviços aos clientes finais". Na visão do autor, quanto mais eficiente for a gestão da cadeia de suprimentos, maiores serão as possibilidades da empresa ter sucesso no mercado, uma vez que se eliminam aquelas atividades que consomem recursos e não criam valor ao longo da cadeia. Nessa orientação, a vertente que considera a Lean Supply Chain Management (Gestão da Cadeia de Suprimentos Enxuta) se orienta pela busca da eficiência na coordenação das relações. Além disso, ao se analisar a gestão da cadeia de suprimentos em termos estratégicos, é possível aspirar relações de cooperação entre os parceiros que a integram, o que permite maior rapidez e eficiência nas transações e, conseqüentemente, o aumento de lucros da empresa.

No entanto, conforme destacam Halldorsson et al. (2007), ainda existe a carência de uma base teórica sócio-econômica que pode ser utilizada para explanar e entender o arranjo inter organizacional proposto pela gestão da cadeia de suprimentos. Desta forma, torna-se válido identificar e discutir teorias que sejam aplicadas às relações entre instituições que formam uma cadeia de fornecimento, visando fornecer um escopo teórico analítico ao seu estudo.

Nesse artigo são propostas duas teorias organizacionais, integrantes da área da Nova Economia Institucional (NEI), cujo escopo analítico pode ser utilizado na compreensão de relações inter organizacionais de uma cadeia de suprimentos: a Teoria dos Custos de Transação (TCT) e a Teoria dos Custos de Mensuração (TCM). Ambas as teorias são direcionadas para a compreensão básica dos aspectos que influenciam a escolha de estruturas de governança. Além dessas, a Visão Baseada em Recursos (VBR) também pode ser válida no entendimento do sistema de geração de valor e definições de estratégias competitivas em contextos de interdependência, característicos da cadeia de suprimentos.

Diante disso, o objetivo desse ensaio teórico é compreender como a cadeia de suprimentos pode ser explicada a partir dos pressupostos presentes nas teorias da TCT, TCM e VBR. Sua validade se estabelece frente à necessidade de se entender os aspectos que determinam a escolha das estruturas de governança a serem utilizadas nas transações entre os segmentos integrantes da cadeia de fornecimento, bem como fornecer subsídios para avaliar se essas estruturas estão sendo empregadas de modo eficiente. Além disso, a percepção da influência de recursos e capacidades diferenciadas as quais determinam heterogeneidades que podem afetar o desempenho entre os agentes da cadeia de suprimentos, justificam a consideração da VBR no entendimento das relações inter e entre segmentos. Em termos metodológicos, a presente pesquisa é bibliográfica e de natureza qualitativa, uma vez que se busca uma interpretação dos pressupostos teóricos envolvidos. Além disso, pode ser classificada como do tipo descritiva e exploratória, apresentando um recorte transversal.

Para atender ao objetivo proposto, além desta introdução, este artigo apresenta uma segunda seção, em que se busca discutir o referencial teórico empregado na presente investigação. Nessa seção, um tópico é destinado a discutir o funcionamento de uma cadeia de suprimentos, abrangendo características básicas de uma Lean Supply Chain Management. Um segundo tópico trata sobre a NEI, especificando duas de suas abordagens, a TCT e a TCM, propostas nesse artigo para a obtenção de um melhor entendimento da gestão da cadeia de suprimentos. Num terceiro tópico são apresentados os princípios básicos da VBR. A terceira seção é destinada à discussão de como cada uma dessas abordagens pode contribuir para o funcionamento mais eficiente da cadeia de suprimentos e para a implementação do 
pensamento lean na sua forma de gestão. Na quarta seção são realizadas as conclusões encontradas e, por fim, são indicadas as referências utilizadas.

\section{2}

\section{REFERENCIAL TEÓRICO}

\subsection{CADEIA DE SUPRIMENTOS}

Segundo Pires (1998), a cadeia de suprimentos é uma distribuição de processos que pode se dar desde o produtor, passando pela indústria processadora, pelo distribuidor até chegar ao cliente final. Pode ser enxergada como um modelo competitivo estratégico e gerencial para as empresas industriais, definido como a integração holística dos processos de negócios por meio da cadeia produtiva, com o objetivo de atender o consumidor final mais efetivamente, isto é, sendo eficiente e eficaz de forma simultânea.

A cadeia de suprimentos não é linear, mas sim uma estrutura ou rede caótica de empresas que satisfazem pedidos dos seus clientes. Conforme destacam Guasseli e Abreu (2009), ao logo do continuum de uma cadeia de fornecimento podem ser identificados três fluxos, que são determinantes para o desempenho dessa cadeia e, também, para a riqueza da organização: o fluxo de materiais (do fornecedor para o cliente), o fluxo de dinheiro (do cliente para o fornecedor) e o fluxo de informação (tanto do fornecedor para o cliente, como do cliente para o fornecedor).

Entre os desafios ou dificuldades a serem transpostas pela gestão da cadeia de suprimentos, Pinto (2006) identifica a acumulação de estoques e de tempo para camuflar problemas de qualidade e falhas no planejamento, escondendo as verdadeiras causas que explicam o porquê essas falhas ocorrem. Além disso, segundo o autor, ocorre a ausência de integração e colaboração entre os diferentes parceiros da cadeia de fornecimento, uma vez que muitas empresas ainda insistem na estratégia de agirem sozinhas, perdendo oportunidades de melhoria que a colaboração em rede ao longo da cadeia poderia gerar.

\subsubsection{Lean Supply Chain Management}

Para responder aos desafios supracitados, Pinto (2006) mostra que oportunidades podem ser vistas através da aplicação do pensamento Lean à gestão da cadeia de suprimentos. Segundo o autor, o objetivo de uma Lean SCM é satisfazer os cinco Cs (5CS) da logística, ou seja: o material certo, no momento certo, nas condições certas, no local certo e no tempo certo. O objetivo é eliminar gradualmente todas as formas de desperdício na gestão da cadeia de suprimentos.

Como princípios impulsionadores para a lean $S C M$, o autor cita práticas como a melhoria contínua, o outsourcing estratégico (terceirização), o envolvimento de fornecedores, juntamente com a conectividade com o cliente, a informação atualizada e correta e o trabalho em equipe. Esses princípios possibilitam uma maior rapidez, melhor qualidade e menores custos uma vez que se tem o produto certo, no local certo e no momento certo.

Para desenvolver uma lean SCM, Sabri e Beamon (2000) trazem um enfoque especial para o desenvolvimento de fornecedores. Nesse aspecto, defendem a construção de relações de longo prazo e de benefício mútuo, que deixam de ser uma opção e passam a ser uma obrigação das organizações que querem ser enxutas. Com isso, boas práticas começam a se fazer necessárias, envolvendo relações e planejamento de longo prazo, sempre no sentido de partilhar uma visão comum e desenvolver planos conjuntos com os fornecedores. Nesse caso, a transferência de conhecimento e de dados, bem como a partilha de riscos e de ganhos 
entre as partes envolvidas também se fazem elementos necessários para o desenvolvimento de fornecedores.

Para a lean SCM ser implementada, Pinto (2006) chama atenção para a necessidade de preparar pessoas capazes de desenvolver a filosofia lean thinking de um modo natural. As lean people, como identificadas pelo autor, são o fator mais importante e decisivo na organização que aplica o pensamento lean, pois de nada adianta ter tecnologias e soluções, se não se tem pessoas adequadas para aplicá-las.

Cabe observar que o processo de articulação proposto pelos autores pode ser melhor entendido ao se considerar os intervenientes que estão envolvidos nas relações de troca. Nesse aspecto, em primeira análise, não se trata apenas da entrega de material, mas da transferência de direitos, na linguagem de Barzel (2005), de direitos de propriedade. Nessa condição, as ações buscando essa articulação devem considerar que as relações entre os segmentos precisam ser suportadas por estruturas adequadas de coordenação, de forma a garantir direitos sobre os produtos transacionados.

A construção dessas estruturas envolve não apenas a consideração dos atributos que envolvem as transações entre os agentes da cadeia de suprimentos, mas a consideração de mecanismos de formalização e seus fatores relevantes, como frequência, comportamentos e interesses estratégicos. Diante disso, nas próximas seções discute-se esse tema sob o olhar de enfoques teóricos considerados complementares a esse estudo, com intuito de melhor compreender os aspectos que influenciam os resultados ao se considerar a cadeia de suprimentos.

\section{$2.2 \quad$ NOVA ECONOMIA INSTITUCIONAL}

A Nova Economia Institucional (NEI) tem sido uma das perspectivas científicas mais debatidas recentemente no mundo acadêmico nas ciências sociais no Brasil. Com suas origens no velho institucionalismo, sobretudo americano, com Veblen e Galbraith, a NEI mantêm certos pressupostos da escola neoclássica. No entanto, considera que esta escola não deu relativa importância ao papel das instituições e, com isso, propõe incluir as instituições no centro do modelo analítico (GOMES, 2004).

De acordo com Zylbersztajn (2009), a NEI propõe duas vertentes analíticas complementares aplicáveis ao estudo das organizações. A primeira pode ser vista como de natureza macro-desenvolvimentista, que focaliza a origem, estruturação e mudanças das instituições. Neste nível, "a questão central é explicar a origem e mudanças das instituições, vistas como as regras que pautam o comportamento da sociedade" (ZYLBERSZTAJN, 2009, p. 50).

A segunda, conforme o autor é de natureza micro institucional, representada pela economia das organizações, que estuda a natureza explicativa dos diferentes arranjos institucionais observados. Em consonância, Azevedo (2000) destaca que a segunda vertente, que foca o nível micro analítico, abrange a Teoria dos Custos de Transação (TCT) e a Teoria dos Custos de Mensuração (TCM). Essas são focadas na análise de estruturas de governança, contemplando as microinstituições, ou seja, aquelas que regulam transações específicas entre agentes.

Além dessas abordagens, mais recentemente, alguns estudos têm buscado na Visão Baseada em Recursos (VBR) fundamentos teóricos sobre a configuração de estruturas de governança. Williamson (2002), em sua obra Strategy research: governance and competence perspectives, admite que a história da firma e os seus recursos, aspectos trabalhados pela VBR, influenciam na escolha da estrutura de governança adequada e, conseqüentemente, nos 
limites da firma. Na seqüência, são apresentados os princípios básicos de cada uma dessas abordagens e a sua relação com as características da gestão da cadeia de suprimentos.

\subsubsection{Teoria dos Custos de Transação}

A TCT surgiu com Ronald Coase que introduziu em seu célebre artigo "The nature of the firm", em 1937, uma nova perspectiva para o entendimento das estratégias empresariais ao mostrar que existem custos, além dos custos de produção, associados ao funcionamento dos mercados: os custos de transação. Em um novo artigo, intitulado "The Problem of the Social Cost", em 1960, Coase agrega a discussão dos direitos de propriedade aos custos de transação. Segundo ele, direitos de propriedade bem definidos diminuem os custos de transação e se constituem em um mecanismo eficiente para lidar com as externalidades econômicas.

Para Zylbersztajn (2009), Coase introduziu uma mudança de paradigma na teoria econômica implantando um novo marco teórico, ao discutir "as razões explicativas para a existência da firma com base nos custos comparativos da organização interna e de produção via mercado, lançando as bases para o estudo das formas alternativas de organização das firmas contratuais" (ZYLBERSZTAJN, 2009, p. 42).

Nas décadas de 1970 e 1980, a partir dos trabalhos realizados por Coase, Williamson (1985) impulsiona a questão dos custos de transação dentro da literatura econômica. A partir da visão da firma como um nexo de contratos, segundo Zylberztajn (2009, p. 43), esses autores abriram a possibilidade do "“...] estudo das organizações como 'arranjos institucionais' que regem as transações, seja por meio de contratos formais ou de acordos informais, os primeiros amparados pela lei, o segundo amparado por salva guardas reputacionais e outros mecanismos sociais".

Sendo assim, apresentando a transação como unidade de análise, a TCT tem como objetivo controlar os direitos de propriedade por meio do alinhamento de estruturas de governanças. O conceito de estrutura de governança, segundo Williamson (1996, p. 58), está relacionado à forma de coordenação das atividades econômicas resultantes da relação inter organizacional. As estruturas de governança podem ser classificadas em: 1) a opção pela compra no mercado; 2) a produção própria, sob a forma hierárquica (integração vertical); 3) a forma híbrida (contratos). A TCT apresenta a função e coordenar estas estruturas a partir da presença de atributos de transação e pressupostos comportamentais.

Conforme destaca Williamson (1985), os atributos que caracterizam uma transação são três: a frequência, a incerteza e a especificidade de ativos, sendo este último o principal determinante da estrutura de governança a ser adotada. Segundo o autor, o atributo frequência diz respeito ao número de vezes que os agentes econômicos se encontram para realizar uma determinada transação. A incerteza, por sua vez, são as mudanças que surgem da complexidade do ambiente econômico, impossibilitando a realização de avaliações totalmente precisas. Já os ativos específicos são ativos tangíveis ou intangíveis irrecuperáveis, no sentido de que não podem ser devolvidos para o mercado caso a relação de negócio original seja descontinuada, ou seja, não podem ser reempregáveis em outra transação sem perda de valor (WILLIAMSON, 1985).

Além dos atributos das transações, Williamson (1985) afirma que a Teoria dos Custos de Transação parte de dois pressupostos comportamentais que a distinguem da abordagem tradicional: o oportunismo e a racionalidade limitada. Em outras palavras, assumese que os indivíduos são oportunistas e que há limites em sua capacidade cognitiva para processar a informação disponível.

A coordenação ocorre a partir da combinação das estruturas de governança com os 
atributos de transação e pressupostos comportamentais. Na estrutura de governança via mercado, conforme Williamson (1985), o nível de especificidade de ativos é baixo, logo, os custos de transação são mínimos. Os agentes conhecem as características dos produtos transacionados, a incerteza e a frequência nas transações são mínimas e, normalmente, não se cria reputação entre os agentes. A integração vertical ou hierarquia, por sua vez, é motivada pelo alto nível de frequência, de incerteza e, principalmente, de especificidade de ativos, que pode atingir seis ramificações: locacional, temporal, humana, de marca, física e dedicada (WILLIAMSON, 1985, 1991).

Já os contratos ou formas híbridas, de acordo com Ménard (2004) e Zylbersztajn (2005), referem-se aos arranjos de coordenação das transações que se diferem das estruturas via mercado e integração vertical. Eles podem ser necessários para garantir que não haja captura da quase renda pelas partes envolvidas, ou seja, para garantir que não ocorra a perda ou expropriação do valor econômico do produto ou serviço transacionado. Segundo Ménard (2004), na medida em que as partes vão se conhecendo, aumenta o uso de mecanismos informais, tais como reputação, confiança, compartilhamento de informações e ajuda mútua, que são utilizados na coerção dos agentes. Essa perspectiva complementa o modelo de Williamson (1991). Na Figura 1, o autor segmenta as formas híbridas em confiança, rede relacional, liderança e governança formal, as duas primeiras próximas da estrutura via mercado e as duas últimas da estrutura hierárquica.

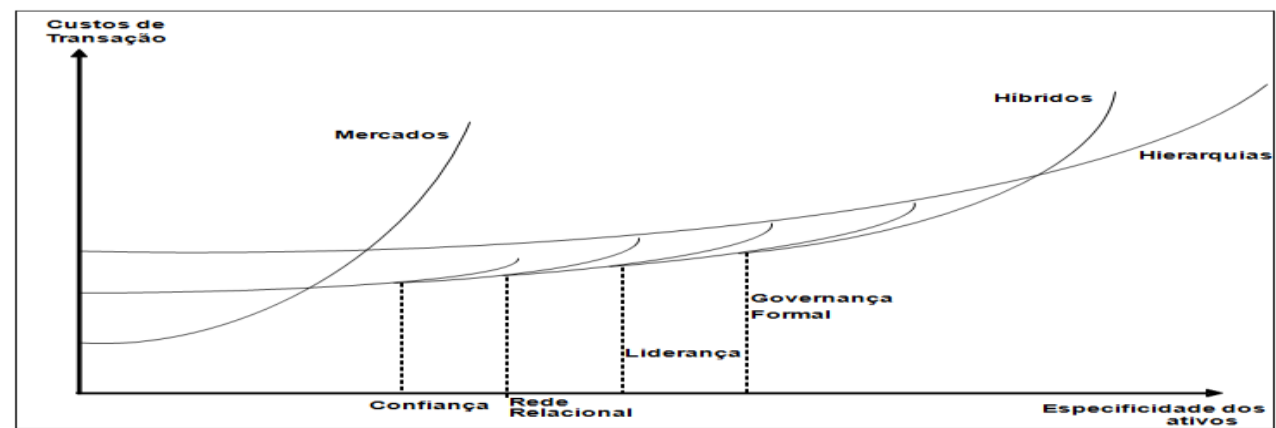

Figura 1 - Estruturas de governança

Fonte: Ménard (2002, p. 22).

Outra questão que deve ser observada são os diferentes níveis de incentivo e de controle que a firma dispõe para organizar suas atividades, discutidos por Williamson (1985) e depois tratados por Mizumoto e Zylbersztajn (2006, p. 150). Segundo os autores, "arranjos via mercado são os que oferecem mais incentivos, mas a possibilidade de controle depende da existência de parceiros substitutos para disciplinar os desvios em relação ao acordo". Sendo assim, conforme a necessidade de controle aumenta, a firma passa a optar por arranjos contratuais em que é possível utilizar a ameaça de litígio para fazer cumprir o contrato. Nesse caso, a firma opta por arranjos hierarquizados em que as atividades são coordenadas internamente, ao preço de um incentivo menor vis-à-vis o arranjo via mercado.

\subsubsection{Teoria dos Custos de Mensuração}

Como a TCT, a Teoria dos Custos de Mensuração (TCM), proposta por Barzel (2001), envolve a coordenação horizontal e vertical, bem como estruturas internas, tendo como foco o objetivo de reduzir custos de transação. No entanto, difere no que se refere aos pressupostos básicos e unidade de análise, além de não apresentar o impacto empírico equivalente. Zylbersztajn (2005) observa que na TCM, a unidade de análise é a transação 
decomposta em dimensões, sendo que um conjunto de direitos econômicos e legais são trocados, sendo o primeiro garantido privadamente e o último pelo estado.

Segundo Barzel (2001), o pressuposto é de que transações que apresentam dimensões

fáceis de mensurar e contratar sejam garantidas pelo Estado, do contrário, meios privados devem ser empregados. Com isso, Barzel (2005, P. 367) traz uma nova perspectiva a partir da TCM. O autor afirma que "a integração vertical é útil quando o custo de mensurar as mercadorias intermediárias é alto", defendendo que "[...] a noção de custo de medição é mais geral do que a de ativos específicos. Também é mais operacional" (BARZEL, 2005, p. 372, tradução nossa).

Para o autor, o aspecto chave dos custos de transação está na mensurabilidade dos atributos dos bens. Tal mensuração pressupõe avaliar não só as dimensões físicas dos atributos do objeto de troca (cor, tamanho, peso, quantidade, dentre outros), como também as dimensões dos direitos de propriedade incluídos na troca. Barzel (2003) constata que a mensuração tem um custo e, em certas situações, o mercado pode ser a instituição mais cara para organizar a produção do que a firma. Sendo assim, a empresa integraria verticalmente quando a dificuldade de se mensurar as mercadorias envolvidas na troca ou de se definir os direitos de propriedade transacionados trouxesse custos de transação elevados.

\subsection{VISÃO BASEADA EM RECURSOS}

De acordo com Mintzberg et al. (2000), a Visão Baseada em Recursos (do inglês, Resource-Based View - VBR) tem sua origem na teoria econômica, especialmente a partir dos estudos de Penrose (1959), que defendeu que as empresas desenvolvem suas vantagens competitivas por meio das imperfeições do mercado. Essas imperfeições geram singularidades que provêem a base para o desenvolvimento de novos produtos e, simultaneamente, de capacidades ou recursos únicos.

Apesar da constatação de Penrose, esses ativos só passam a ser considerados de forma efetiva pela VBR a partir do trabalho de Wernefelt (1984). Nesse trabalho é estabelecido um paralelo entre a visão tradicional baseada em produtos, defendida pelo modelo competitivo de Porter (1985), e a VBR. As ideias de Wernefelt não decolaram até 1990, quando Prahalad e Hamel popularizaram sua visão a respeito de capacidades dinâmicas (MINTZBERG, 2000).

Barney (1991) vem ao encontro dos argumentos de Wernefelt (1984) e amplia a perspectiva original de Penrose, afirmando que o conjunto de recursos da firma não é somente uma lista de fatores, mas o processo de interação entre esses recursos e os seus efeitos sobre a organização. Na visão de Barney (1991), para serem estratégicos, os recursos devem ser valiosos, raros, imperfeitamente imitáveis e insubstituíveis, de modo a possibilitar que a empresa crie e siga estratégias eficazes. Eles podem ser classificados como recursos de capital físico (tecnologia, fábrica, equipamentos, localização geográfica, acesso a matériasprimas), recursos de capital humano (treinamento, experiência, inteligência, relacionamentos) e recursos de capital organizacional (sistemas e estruturas formais, bem como relações informais entre grupos).

Após Barney (1991), Peteraf examina as condições dos recursos que asseguram as vantagens competitivas sustentáveis, em seu artigo The cornerstones of competitive advantage, publicado em 1993. Na visão da autora, os recursos rendem uma vantagem competitiva sustentável para a empresa quando apresentam: a) superioridade, no sentido de serem heterogêneos, para garantir a obtenção de lucros diferenciais; b) barreiras ex post à competição, ou seja, serem difíceis de imitar devido a mecanismos de isolamento presentes; 
c) barreiras ex ante à competição, em que assimetrias de informação são necessárias para limitar a competição explícita pelos recursos; d) imobilidade, quando possuírem especialização ou especificidade que os tornam adaptados exclusivamente para suas necessidades.

Tendo como base a presença de recursos e capacidades diferenciadas, conforme destaca Saes (2009), a RBV indica que as vantagens competitivas são provenientes de atividades ocorrendo nas rotinas, processos, posições e caminhos da empresa, os seus path dependencies. Em outras palavras, a vantagem competitiva é proveniente da memória, do aprendizado e dos caminhos trilhados pela organização ao longo do tempo (WERNEFELT, 1984).

Nesse contexto, as rendas diferenciais fluem de ativos específicos da firma, que não podem ser imediatamente replicados: são rendas ricardianas. Segundo Saes (2009), o conceito de rendas ricardianas deriva do trabalho de David Ricardo. Ao analisar a produção agrícola, Ricardo observou que o preço do produto agrícola seria determinado pela oferta de terra e de sua fertilidade. Nesse aspecto, quanto maior a fertilidade, maior a renda para o produtor que possui a terra fértil. Portanto, essas rendas são devidas a fatores valorizados, mas inerentemente raros e difíceis de obter.

Nota-se que diversos estudiosos têm focado seu trabalho na descrição dos recursos e capacidades estratégicos inerentes ao ambiente interno das organizações. Ainda que diversos progressos tenham sido alcançados, desde os pensadores clássicos como Penrose (1959), Wernefelt (1984), Barney (1991) e Peteraf (1993), com seu foco nas relações intraorganizacionais, evidencia-se a necessidade da continuidade dos estudos na área, dadas as limitações ainda discutidas para aplicação empírica do modelo.

\section{DISCUSSÃO DOS RESULTADOS}

\subsection{Cadeia de Suprimentos e TCT}

Segundo Grover e Malhotra (2003), pouco se tem abordado a TCT na gestão de operações. Em particular, existe um número considerável de oportunidades dentro da disciplina de gestão de operações para avaliar a cadeia de suprimentos, muitas delas relacionadas com a perspectiva da TCT. Focando a eficiência econômica, a TCT traz uma visão de coordenação necessária à gestão de diversas atividades, unidades internas e parceiros de negócio que envolve a cadeia de suprimentos (GROVER; MALHOTRA, 2003). Sendo assim, em um contexto de interdependência entre os segmentos, tal como é o da cadeia de suprimentos, a TCT pode contribuir a partir de seu escopo teórico e analítico com o fornecimento de predições a respeito de como as transações devem ser governadas, ou como podem ser estruturadas as relações entre os segmentos da cadeia.

Seguindo esse raciocínio, Lazzarini, Cook e Chadad (2001) destacam a necessidade de governar as transações entre os agentes de forma a viabilizar os planos produtivos de uma cadeia de suprimentos. Isso quer dizer que para um processador programar sua produção, ele tem que alinhar planos de fornecimento e atendimento a uma demanda do segmento de distribuição, considerando as sazonalidades no consumo. Nesse caso, a melhor coordenação, resultante de alinhamento estratégico entre os segmentos da cadeia, pode gerar redução nos custos de transação.

Para Farina (1999), governar as transações significa incentivar o comportamento desejado e, ao mesmo tempo, conseguir monitorá-lo. Essa governança pode ser obtida pelo sistema de preços (governança via mercado), quando o produto desejado tem baixa 
especificidade e é ofertado por vários produtores. Caso contrário, a governança adequada pode exigir a elaboração de contratos onde ficam pré-definidos instrumentos de incentivo e controle, tais como multas, auditorias ou prêmios por resultado. Dito de outra forma:

[...] estratégias competitivas dependem de estruturas de governança apropriadas para que possam ser bem sucedidas. Por esse motivo, a capacidade de coordenação vertical torna-se elemento constituinte tanto da competitividade estática quanto da competitividade dinâmica. É essa coordenação que permite à empresa receber, processar, difundir e utilizar informações de modo a definir e viabilizar estratégias competitivas, reagir a mudanças no meio ambiente ou aproveitar oportunidades de lucro (FARINA, 1999, p. 24).

Desta forma, a coordenação pode ser obtida na relação intersegmento a partir de estruturas de governança apropriadas. Ao se detalhar melhor essas estruturas e o escopo teórico analítico da TCT, é possível considerar que os atributos de transação, relacionados à incerteza, frequência e especificidade de ativos, bem como os pressupostos comportamentais, cujo enfoque se dá sobre a racionalidade limitada e a possibilidade de comportamento oportunista dos agentes, afetam a forma como as firmas organizam suas relações na cadeia de suprimentos.

Tendo-se em vista o atributo frequência, é possível afirmar que quanto maior a frequência, menores são os custos relacionados à coleta de informações e à elaboração de contratos, e maior a probabilidade de os parceiros desenvolverem reputação, limitando comportamentos oportunistas (WILLIAMSON, 1985). Nesse caso, os agentes envolvidos em transações recorrentes na cadeia de suprimentos podem se beneficiar com a criação de reputação e, consequentemente, com a redução dos custos de transação. Sendo assim, torna-se válida a afirmação de Sabri e Beamon (2000) e de Pinto (2006) sobre a importância de se desenvolver relações de longo prazo e de beneficio mútuo com os fornecedores ao se considerar a cadeia de suprimentos, principalmente quando se trata da incorporação do pensamento lean na gestão da cadeia.

No que se refere à incerteza, vale destacar os exemplos citados por Turban, Mclean e Wetherbe (2004) como fonte de problema na cadeia de suprimentos. Conforme os autores, uma fonte importante de incertezas nessa cadeia é a previsão de demanda, que está sujeita à influência de fatores como concorrência, preços, condições climáticas, entre outros. Além das incertezas relacionadas à demanda, existem também as incertezas relacionadas ao fornecimento, tais como atraso na entrega, problemas de qualidade nos insumos e outras.

$\mathrm{Na}$ visão de Williamson (1985), quanto maior a incerteza, advinda das mudanças que surgem da complexidade do ambiente econômico, e da consequente impossibilidade de avaliações totalmente precisas, mais complexo se torna o desenvolvimento de parcerias de longo prazo. Nessa situação, a criação de instituições para reduzir as incertezas, relativas ao comportamento e ao comprometimento dos atores em relacionamento (NORTH, 1991), pode ser válida no estabelecimento de sanções em caso da falta de cumprimentos de acordos entre os agentes da cadeia de suprimentos.

Os ativos específicos, por sua vez, influenciam a gestão da cadeia de suprimentos por perderem valor caso a relação de negócio seja descontinuada entre as partes que transacionam (WILLIAMSON, 1985). Em outras palavras, a presença desse tipo de ativo requer dos atores envolvidos estruturas de governança mais integradas verticalmente, na tentativa de controlar e proteger esses ativos contra comportamentos oportunistas.

Em relação aos pressupostos comportamentais, é válido notar que tanto a racionalidade limitada quanto a possibilidade de comportamento oportunista podem interferir 
nas transações da cadeia de suprimentos. No caso da racionalidade limitada, como os agentes dessa cadeia não são capazes de obter um conhecimento completo e antecipado das consequiências advindas de cada escolha realizada, a elaboração dos contratos se torna limitada frente à impossibilidade de se processar a totalidade das informações. Desta forma, podem se originar custos de transação mais altos, já que surge a necessidade de especificar um contrato incompleto entre as partes, forçando-as a incorrer em despesas associadas a negociações em curso sobre especificações de contrato e preços dos produtos transacionados, além dos gastos econômicos da gestão desse contrato. Esses custos, conforme a TCT, podem ser minimizados através de uma escolha correta de relação interfirmas, o que pode ser realizado pelos gestores das empresas que integram a cadeia de suprimentos, ao definirem os mecanismos de governança a serem utilizados.

No que tange a possibilidade de comportamento oportunista, é valido notar que esse segundo aspecto comportamental, discutido pela TCT, deve ser monitorado e, se possível, evitado entre as partes componentes da cadeia de suprimentos. Conforme destacam Bello, Lohtia e Sangtani (2004), a manutenção dos problemas relativos ao risco do oportunismo em contratos entre os parceiros comerciais inibe e motiva as firmas a evitar, preventivamente, potenciais investimentos improdutivos. Assim, a confiança entre as partes envolvidas não pode ser estabelecida simplesmente a partir da existência de um contrato: todo contrato implica riscos, devendo ser constantemente revisto pelas partes interessadas. Com isso, a presença do oportunismo em algumas partes da cadeia incita vigilância constante, aumentando os custos de transação. No entanto, em médio prazo, quando um padrão é estabelecido e mecanismos de salvaguarda são determinados, estes custos tendem a diminuir e, em alguns casos, tornarem-se irrisórios, conforme já observado por Barzel (2005).

Um aspecto determinante ao se considerar o comportamento oportunista refere-se à assimetria de informação. Conforme Akerlof (1970), primeiro, pode haver um oportunismo ex ante, no qual a informação está escondida antes da realização de uma transação. $\mathrm{O}$ autor caracteriza essa situação como adversa, ou seja, uma situação de assimetria informacional na qual o vendedor pode dispor de informações sobre defeitos em um produto antes da realização da transação e não disponibilizá-la ao potencial comprador. Como resultado, o vendedor pode agir de forma oportunista, ao não revelar esses defeitos antes da operação. Informações ocultas podem levar à seleção adversa e a problemas de comportamento oportunista. Nesse caso, o direito contratual pode atenuar o problema da seleção adversa, fornecendo uma maior proteção para o comprador.

Um segundo caso, conforme Akerlof (1970), refere-se ao oportunismo ex-post, que acontece após uma transação devido a ações ocultas dos indivíduos ou firmas nela atuantes. Estas partes podem ter incentivos para agir de forma oportunista a fim de aumentar o seu bem-estar econômico, visto que suas ações não são diretamente observáveis por outros participantes da cadeia. Em contrapartida, quando há o compartilhamento de informação, que vai além de dados sobre transações de compra e venda, incluindo aspectos estratégicos orientados ao planejamento conjunto, permite-se que as empresas participantes da cadeia façam o que é certo de maneira mais rápida e eficiente (BOWERSOX; CLOSS, 2001). Essas situações opostas demonstram que o oportunismo pode estar presente na cadeia de suprimentos através da assimetria de informação entre as firmas participantes, e ressalta a importância da elaboração e monitoramento de cláusulas contratuais específicas a cada transação.

Desta forma, os pressupostos da racionalidade limitada e oportunismo são facetas distintas da TCT e, juntos, dão origem a custos de transação (COASE, 1937, 1960) que incidem sobre as firmas participantes da cadeia de suprimentos. Para organizar as operações, e 
buscar a minimização desses custos, os gestores devem utilizar dos mecanismos de governança adequados, alinhados a esses pressupostos comportamentais, bem como aos atributos de transação apresentados. Como as partes transacionam por meio de contratos, se faz necessário que esses apresentem salva-guardas contratuais capazes de minimizar os efeitos negativos resultantes da presença desses fatores.

Em suma, reconhece-se que as transações realizadas entre firmas que pertencem a uma cadeia produtiva são permeadas de complexidade e incerteza - tanto econômicas quanto operacionais. Dada a limitação cognitiva, os agentes econômicos são incapazes de antecipadamente prever e estabelecer medidas corretivas para qualquer evento que possa ocorrer quando da realização de uma transação. Aliada a limitação cognitiva, a possibilidade de comportamento oportunista, e os atributos de transação discutidos surgem como fatores que podem afetar no relacionamento dos agentes na cadeia. Desta forma, pela TCT, as firmas atuantes em uma mesma cadeia de suprimentos podem ser vistas como um conjunto de contratos, formais ou informais, devendo considerar as dificuldades derivadas das suas condutas futuras e garantir que os compromissos sejam honrados dentro da continuidade da sua interação.

\subsection{Cadeia de Suprimentos e TCM}

A consideração da relação entre as Teorias que envolvem os estudos da cadeia de suprimentos e a teoria dos custos de mensuração podem ser tratadas sob três perspectivas: na busca de estruturas de governança delineadas para se garantir direito de propriedade nas transações; no direito de controle; na geração de informação.

Em relação às estruturas de governança, ao se verificar que os atributos presentes se configuram em dimensões mensuráveis, o direito legal se apresenta e a possibilidade de formalizar um contrato permite que as organizações possam terceirizar suas atividades. Nesse caso, uma atividade logística e de suprimentos, por exemplo, pode ser contratada em situações nas quais a mensuração possa ocorrer, garantindo os direitos legais entre os contratados. A existência de dificuldades de mensuração das dimensões presentes poderia levar à internalização das atividades na empresa (integração vertical).

Nota-se que, aspectos acordados, tratados pelo direito econômico, podem ser de difícil comprovação, podendo levar a perdas para as empresas envolvidas em uma transação na cadeia de suprimentos. Dessa forma, surgiriam custos de transação, relacionados à busca de garantias dos direitos entre as partes, gerando ineficiências no processo de coordenação das ações e perdas de valor, associadas ao nível de serviço ou geração de novos custos.

Quanto ao controle, Hart e Moore (1990) observam que a abordagem dos direitos de propriedade considera que a posse de direitos de controle é fundamental para a decisão de integrar. Conforme eles, a obtenção de lucros a partir de uma segunda firma (profit stream) pode ser realizada por contratos, mas se o objetivo é ter controle faz-se necessário integrar suas atividades (residual control rights). Sendo assim, Zylbersztajn (2005, p. 6, tradução nossa) conclui: "Dessa forma, o controle efetivo está associado com a integração vertical, enquanto transações de mercado são escolhidas quando baixa especificidade de ativos prevalece, deixando menos espaço para expropriação".

Nota-se que o controle efetivo permite que a quebra de promessas não ocorra, notadamente em relações de longo prazo (BARZEL, 2005). Entretanto, a condição de longo prazo pode propiciar perda da mensuração ao longo de tempo, dada a construção de relações de confiança (frequência na transação). As falhas advindas da falta de mensuração, por sua vez, podem trazer perdas tanto financeiras como de reputação (moral hazard) para a empresa, 
aumentando os custos pela não realização desses controles (aumento de lead time, custo de pessoal, a perda de produto, dentre outros).

Assim, a realização de contratação pode minimizar essas ocorrências, entretanto, para ser efetiva precisa ser objetivamente mensurável e verificável (BARZEL, 2005). Conforme afirma o autor, dimensões que são fáceis de mensurar estimulam a contratação, dimensões de difícil mensuração (atributos mais efêmeros, por exemplo), por sua vez, podem requerer a decisão judicial, ou se utilizar de acordos de longo prazo de forma a negociar ao longo do tempo a aquisição dessas dimensões.

Entretanto, mais do que estabelecer mecanismos de controle, as empresas necessitam efetivar ações articuladas, dado que a ineficiência nas relações entre segmentos são geradoras de perdas competitivas que se estendem em toda cadeia produtiva. Conforme observa Farina (1999) as estratégias competitivas podem ser barradas por gargalos presentes na cadeia produtiva. Dessa forma, a identificação efetiva das dimensões mensuráveis e a adoção de mecanismos eficientes de controle dessas atividades podem viabilizar as estratégias individuais e coletivas. Esses mecanismos contribuem para minimizar os gargalos da cadeia de suprimentos, os quais na sua ausência tenderiam a serem resolvidos apenas pela integração vertical. Dito de outra forma, se não ocorre articulação com outros agentes com influencia nas ações estratégicas, uma alternativa é a empresa realizar ela mesma as ações necessárias.

Da mesma forma, a geração de informação depende de mecanismos eficazes de controle das dimensões presentes nas transações, envolvendo os segmentos envolvidos em relações de interdependência seqüencial. A formalização em estruturas contratuais de governança permite que, mesmo na ausência do direito efetivo de controle, o direito residual de controle exista, e um mecanismo eficaz de transferência de informações possa ocorrer. Isso pode permitir que os resultados estratégicos aconteçam ou que um comportamento desejado seja estimulado, limitando o efeito de objetivos conflitantes no desempenho dos integrantes do sistema. Em suma, uma adequada estrutura de governança permite melhoras no sistema de informação.

Nota-se que a assimetria de informação gera problemas relacionados a dificuldades de mensuração e a proteção de direitos de propriedade. A mensuração e a informação possibilitam a desintegração da empresa, formando a cadeia produtiva. Dito de outra forma, a empresa pode escolher desenvolver todas as atividades necessárias ao atendimento da demanda ou buscar parceiros para desenvolver atividades que vão configurar a cadeia de suprimentos da empresa. Isso se torna extremamente eficiente na busca de capacidades tanto produtivas quanto estratégicas.

Nesse sentido, a informação, para Barzel (2005), se estabelece como essencial para garantia dos direitos de propriedade, influenciando na decisão de integrar ou não as atividades. Sem informação não há definição do que se possui. Além disso, estabelece significado para os direitos econômicos sobre um produto, tanto em termos de padrão de processo, como de valor. Para o autor, desde que as informações são incompletas, direitos individuais não são claramente delineados, o que acaba gerando custos adicionais (custos de transação). A integração vertical definiria um arranjo adequado na ausência ou limitação de informações ou para sua transmissão efetiva quando envolve diferentes estágios. A mensuração, nesse aspecto, caracteriza para Barzel (2005) uma particular forma de informação.

Cabe observar que a Teoria dos Custos de Mensuração está preocupada com o direito de propriedade, ou seja, é necessário controlar e mensurar para garantir esses direitos. Nesse sentido, o direito de propriedade, o controle, a informação, e sua adequada estrutura de governança, podem permitir não apenas a redução de custos de transação, mas que estratégias 
individuais sejam incorporadas ou inseridas no contexto da cadeia de suprimentos. Dessa forma, a mensuração e sua influência na configuração das estruturas de governança identifica o caminho para entendimento do efeito de direitos de propriedade. Além disso, ratifica a necessidade de mensuração efetiva para gerar controle, informação e envolvimento em ações estratégicas na gestão da cadeia de suprimentos de forma geral, ou particularmente no caso da proposta de lean SCM.

\subsection{Cadeia de suprimentos e VBR}

Outro aporte teórico que pode ser utilizado no entendimento do arranjo inter organizacional proposto pela cadeia de suprimentos é a VBR. De acordo com essa abordagem, são os recursos e capacidades diferenciadas de uma empresa que possibilitam a conquista de vantagens competitivas sustentáveis. Sendo assim, as vantagens surgem porque as organizações adquirem e desenvolvem um conjunto de recursos que são superiores aos de seus concorrentes.

Nessa perspectiva, a VBR pode ser válida no entendimento do sistema de geração de valor e definições de estratégias competitivas em contextos de interdependência, típicos da cadeia de suprimentos. Considerada por alguns autores (PIRES, 1998; PINTO, 2006) como um modelo estratégico e gerencial com o objetivo de coordenar diversos elos de um sistema produtivo, a cadeia de suprimentos é afetada pela gestão de recursos e capacidades que se distribuem ao longo da cadeia e em cada firma individual.

Conforme destaca Langlois (1992, p.109, tradução nossa), "nenhuma empresa mesmo as mais e integradas - tem as capacidades necessárias para todas as atividades da cadeia de produção". Sendo assim, o resultado é que as empresas devem articular-se com outras empresas que possam lhes fornecer as capacidades necessárias. Para explicar a lógica da decisão da empresa terceirizar ou não suas atividades, Argyres e Zenger (2008, p. 6, tradução nossa) afirmam: "as empresas governam internamente capacidades comparativas e terceirizam o acesso às capacidades onde a firma é comparativamente incompetente". A partir dessa lógica, percebe-se que as capacidades que a empresa possui determinam os limites da cadeia de suprimentos, uma vez que as decisões de fazer internamente ou terceirizar são tomadas levando-se em conta a sua existência.

Ao focar o alcance de vantagens competitivas sustentáveis por meio de recursos valiosos, raros, imperfeitamente imitáveis e insubstituíveis (BARNEY, 1991) ou superiores, imóveis e com barreiras ex ante e ex post à competição (PETERAF, 1993), a VBR explica como as firmas se tornam heterogêneas frente a especificidade dos recursos por elas possuídos. Conforme Ketokivi e Schroeder (2003), vários estudos empíricos em estratégia de operações utilizam a RBV como base teórica, explorando a heterogeneidade de recursos para explicar a variabilidade do desempenho operacional entre firmas.

Nesse sentido, ao se analisar a cadeia de suprimentos, a heterogeneidade das firmas pode ser válida no sentido de suprimir necessidades especificas ao longo da cadeia, ou identificar necessidades de articulação para geração de capacidades. Quando cada firma se especializa no que faz bem a partir de seus recursos e capacidades idiossincráticas, cria-se condições de melhoramento na realização de atividades especializadas, bem como de geração de rendas ricardianas (SAES, 2009), a partir de fontes diferentes.

Destaca-se, ainda, a interferência de path dependence, ou seja, do aprendizado e dos caminhos trilhados pela organização ao longo do tempo, sobre a cadeia de suprimentos. Argyres e Zenger (2008) afirmam que a distribuição dos recursos nas firmas em um determinado momento reflete uma série de decisões passadas que elas tomaram para 
desenvolver ou não desenvolver capacidades internamente, o que está implícito no processo de aprendizagem pelo qual passaram. O path dependence na cadeia de suprimentos se relaciona ao tratamento das relações construídas entre os agentes ao longo do tempo. Essas relações reduzem as incertezas e viabilizam a continuidade da relação, permitindo a construção de laços sustentados na reputação das partes envolvidas. Nesse âmbito, quanto mais adequada for a coordenação entre fornecedores e clientes maior será a adaptação às mudanças do ambiente, menores serão os conflitos das relações cliente/fornecedor e, portanto, maior será a geração de valor.

\section{$4 \quad$ CONCLUSÃO}

O objetivo da presente investigação foi o de compreender como a gestão da cadeia de suprimentos pode ser entendida a partir dos pressupostos presentes nas teorias da TCT, TCM e VBR. A partir de um estudo de cunho bibliográfico, buscou-se entender a cadeia de suprimentos e sua gestão, a partir das correntes teóricas que suportam tanto o seu processo de organização e estruturação, quanto a definição de caminhos estratégicos envolvendo seus segmentos e agentes.

Quanto à Teoria dos Custos de Transação foi possível perceber que entre cada segmento da cadeia de suprimentos podem existir diferentes estruturas de governança que se alinham aos interesses operacionais ou estratégicos, ou mesmo apenas operacionais dos agentes envolvidos. Com foco na coordenação entre os segmentos que transacionam, essas estruturas são delineadas ao longo da cadeia a partir da consideração de fatores influenciadores, como a frequência com que ocorrem as transações, e a consequente reputação que se desenvolve entre as partes, as incertezas e os ativos específicos envolvidos. Da mesma forma, a existência de racionalidade limitada e a possibilidade de comportamento oportunista afetam as transações entre os agentes, definindo a necessidade de proteger direitos de propriedade. Em suma, quando a empresa deixar de integrar verticalmente e realiza contratos com terceiros, a cadeia de suprimentos é formada e custos de transação podem ser gerados, em função da possibilidade de comportamentos oportunistas, geração de salvaguardas para ativos específicos e busca de proteção de direitos de propriedade.

Da mesma forma, a consideração dos aspectos relacionados a direito de propriedade, controle e informação, tratados por intermédio da Teoria dos Custos de Mensuração, apontam caminhos para articulação na cadeia produtiva. Nesse aspecto, a referida abordagem propõe e justifica as formas de organização capazes de gerar maior dinamismo nas relações entre os agentes na cadeia de suprimentos, a partir da geração de garantias, em função das dimensões transacionadas e suas possibilidades de medição. Dessa forma, a consideração dessa teoria permite que se lance um melhor entendimento acerca dos fatores presentes nas relações de troca e como a utilização de instrumentos de garantia pode permitir que as articulações se realizem e a gestão dos interesses individuais possa gerar estratégias coletivas.

Em síntese, direitos de propriedade demandam sistemas de controle efetivos, sendo que sua proteção envolve formas de garantias (direito legal ou econômico) que, por sua vez, são dependentes das possibilidades de mensuração. Nessa orientação, estruturas de governança adequadas se apresentam como mecanismos de coordenação, que orientados por instrumentos de controle e mensuração, geradores de informação, podem assegurar que os recursos sistêmicos estratégicos gerem os resultados esperados e os direitos de propriedade sejam assegurados. 
Ao se considerar o escopo teórico da Visão Baseada em Recursos, a análise da cadeia de suprimentos, por sua vez, permite entender a configuração dessa cadeia por meio da troca de capacidades existente entre suas empresas integrantes. Dito de outra forma, como nenhuma empresa tem todos os recursos e capacidades necessárias para $\mathrm{o}$ seu funcionamento, elas os trocam entre si para a operacionalização de suas atividades. Partindo dessa lógica, é possível compreender, com o suporte teórico da VBR, que as empresas são heterogêneas em função de seus recursos e capacidades distintos, sendo que, em caso de recursos e capacidades de difícil imitação, é possível a geração de lucros diferenciais (rendas ricardianas). Além disso, ao focar o path dependence, discutido pela VBR, na cadeia de suprimentos, é possível entender a reputação como um recurso estratégico gerado pelos segmentos da cadeia ao longo do tempo.

Desta forma, foi possível perceber que enquanto sob a ótica da TCT, a cadeia de suprimentos pode ser delineada como um conjunto de contratos, a partir da TCM ela pode ser vista como um conjunto de trocas de direito de propriedade que devem ser garantidos. Considerando a VBR, por outro lado, ela pode ser tratada como um conjunto de recursos e capacidades distintos que são trocadas entre si. Com isso, a cadeia de suprimentos é mais que o planejamento e execução do fluxo de materiais, informações e recursos financeiros, conforme preconizam os autores referenciados. Envolve, também, fluxo de estruturas de governança, atributos de transação, comportamentos, direitos de propriedade, recursos e capacidades e, ainda, interesses estratégicos.

A não aplicação empírica desse estudo indica sua limitação. Ademais, novas conexões e interpretações entre a cadeia de suprimentos e as referidas abordagens são possíveis. Dessa forma, possibilidades de investigações futuras podem ser vislumbradas a partir de estudos empíricos envolvendo análises da gestão da cadeia de suprimentos, com base nos pressupostos presentes nas teorias dos custos de transação, dos custos de mensuração e da visão baseada em recursos. 


\section{REFERÊNCIAS}

AKERLOF, G. A. The market for 'lemons': qualitative uncertainty and the market mechanism. Quarterly Journal of Economics, v. 84, p. 488-500, 1970.

ARGYRES, Nicholas; ZENGER, Todd. Capabilities, Transaction Costs, and Firm Boundaries: A Dynamic Perspective and Integration. Social Science Research Network (SSRN). Available at SSRN: Jun/2008.

AZEVEDO, Paulo Furquim de. Nova Economia Institucional: referencial geral e aplicações para a agricultura. Agricultura, São Paulo, v. 47, n. 1, p. 33-52, 2000.

BARNEY, JAY. Firm resources and sustained competitive advantage. Journal of management, v. 17, n. 1, p. 99-120, 1991.

BARZEL, Y. A theory of Organizations to supersede the theory of the firm, set. 2001. Disponível em: <http// www. econ.washington.edu/people/detail.asp?uid=yoramb > Acesso em: 16 jan. 2012.

Standards and the form of agreement. In: 3 International Society for New institutional Economics. Budapeste, Hungria, 2003. Disponível em: http>www.isnie.org. Acesso em: 15 jan. 2012.

Organizational Forms and Measurement Costs. Journal of Institutional and Theoretical Economics, v. 161, p. 357-373, 2005.

BELLO, D. C.; LOHTIA, R., SANGTANI, V. An institutional analysis of supply chain innovations in global marketing channels. Industrial Marketing Management, v. 33, p. 5764, 2004.

BOWERSOX, D. J.; CLOSS, D. J. Logística Empresarial: O Processo de Integração da Cadeia de Suprimento. São Paulo: Editora Atlas, 2001.

COASE, R. The Nature of the Firm. Economica, London, New Series, v. 4, n. 16, p. 386-405, Nov. 1937).

The Problem of Social Cost. Journal of Law and Economics, v. 3, p. 1-44, University of Chicago, Oct. 1960.

FARINA, E. M. M. Q. Competitividade e coordenação dos sistemas agroindustriais: a base conceitual. In. JANK, Marcos Sawaya; FARINA, Elizabeth M. M. Q.; GALAN, Valter Bertini. O agribusiness do leito no Brasil. São Paulo: Editora Milkbizz, 1999.

GOMES, Fábio Guedes. A Nova Economia Institucional (NEI) e o (Sub) Desenvolvimento Econômico Brasileiro: Limites e Impossibilidades de Interpretação. In: SEP - ENCONTRO NACIONAL DE ECONOMI POLÍTICA, 9., 2004, Uberlância. Anais... Uberlândia: 2004. 1. CD-ROM. 
GROVER, V.; MALHOTRA, M. K. Transaction cost framework in operations and supply chain management research: theory and measurement. Journal of Operations Management, v.21, p. 457-473, 2003.

GUASSELli, I. G. G.; ABREU, M. F.. Racionalidade Substantiva como um Recurso Estratégico para a Obtenção de Vantagens Competitivas: O Caso de uma Associação de Fruticultores na 'Serra Gaúcha'. In: 3 Es - ENCONTRO DE ESTUDOS DE ESTRATÉGIA DOS PROGRAMAS DE PÓS-GRADUAÇÃO EM ADMINISTRAÇÃO, 4., 2009, Recife.Anais... Rio de Janeiro: 2009. 1 CD-ROM.

HALLDÓRSSON ET AL. Complementary theories to supply chain management. Supply Chain Management: an international journal, v. 12, n. 4, p. 284-296, 2007.

HART, Oliver; MOORE, John. Property Rights and the Nature of the Firm. Journal of Political Economy, v. 98, n. 6, p. 1119-1158., 1990.

KETOKIVI, M.A.; SCHROEDER, R.G. Manufacturing Practices, Strategic Fit and Performance: A Routine-Based View. International Journal of Operations and Production Management, September 23, 2003.

LANGLOIS, Richard N. Transaction-Cost Economics in Real Time. Oxford Journal Industrial and Corporate Change, v. 1, n. 1, p. 99-127, 1992.

LAZZARINI, S. G.; COOK, M. L.; CHADDAD, F.R. Integrating Supply Chain and Network Analysis: the study of netchains. Journal on Chain And Network Science, v. 1, n. 1, p. 7-22, 2001.

MÉNARD, Claude. The economics of hybrid organizations. Journal of Institutional and Theoretical Economics, p. 345-376, 2004.

MINTZBERG, H. et. al. Safári de Estratégia. Porto Alegre: Bookman, 2000.

MIZUMOTO, Fábio Matuoka; ZYLBERSZTAJN, Decio. A coordenação simultânea de diferentes canais como estratégia de distribuição adotada por empresas da avicultura de postura. Organizações Rurais \& Agroindustriais, Lavras, v. 8, n. 2, p. 147-159, 2006

NORTH, Douglas. Institutions. Journal of Economic Perspective, v. 5, n. 1, p. 97-112, Winter, 1991.

PENROSE, Edith T. The theory of the growth of the firm. New York: Wiley, 1959.

PETERAF, Margaret A. The cornerstones of competitive advantage: a resource based view. Strategic Management Journal, v.14, p. 179-191, 1993. (PIRES, 1998.

PINTO, João Paulo. Pensamento Lean: A filosofia das organizações vencedoras. São Paulo: Lidel, 2006. 
PIRES, Sílvio R. I. Gestão da Cadeia de Suprimentos: Supply Chain Management Conceitos, Estratégias, Práticas e Casos, 2. Ed. 1998.

PORTER, M. The Contributions of Industrial Organization to Strategic Management. Academy of Management Review, v. 6, n. 4, p. 609-620, 1985.

SABRI, E. H.; BEAMON, B. M. A multi-objective approach to simultaneous strategic and operational planning in supply chain design. Omega, v. 28, p. 581-598, 2000.

SAES, Maria Sylvia Macchione. Estratégias de diferenciação e apropriação da quaserenda na agricultura: a produção de pequena escala. São Paulo: Annablume, Papesp, 2009.

TURBAN, E.; MCLEAN, E.; WETHERBE, J. Tecnologia da Informação para Gestão: Transformando os Negócios na Economia Digital. Porto Alegre: Bookman, 2004.

WERNEFELT, BIRGER. A resource- based view of the firm. Strategic Management Journal, v. 5, p.17 -180, 1984.

WILLIAMSON, O. E. The economic institutions of capitalism: firms, markets, relational contracting. New York: Free Press, 1985.

Comparative Economic Organization: the Analysis of Discrete Structural Alternatives. Administrative Science Quarterly, v. 36, p. 269-296, 1991.

The mechanisms of governance. New York: Oxford University Press, 1996.

WILLIAMSON, O. E. The Theory of the Firm as Governance Structure: from choice to contract. 2002. (Working Paper).

ZYLBERSZTAJN, D. Measurement costs and governance: bridging perspectives of transaction cost economics. In: International Society for the New Institutional Economics ISNIE, Barcelona-Espanha, 2005

Papel dos contraltos na coordenação agro-industrial: um olhar além dos mercados. In: SOUZA, José Paulo de; PRADO, Ivanor Nunes do (Org.). Cadeias produtivas: estudos sobre competitividade e coordenação. 2. Ed. Maringá: EDUEM, 2009. 